\title{
Mycoplasma genitalium: an organism commonly associated with cervicitis among west African sex workers
}

\author{
J Pépin, A-C Labbé, N Khonde, S Deslandes, M Alary, A Dzokoto, C Asamoah-Adu, H Méda, \\ E Frost
}

See end of article for authors' affiliations

.....................

Correspondence to: Dr Jacques Pépin, Centre Hospitalier Universitaire, 3001 , 12ème Avenue Nord, Sherbrooke, Québec, Canada J1H 5N4; jacques.pepin@ usherbrooke.ca

Accepted for publication 29 April 2004
Objectives: To identify the contribution of Mycoplasma genitalium to the aetiology of cervicitis in subSaharan Africa and its relative importance in the overall burden of sexually transmitted infections among female sex workers (FSW).

Methods: The study population consisted of FSW recruited in Ghana and Bénin during the initial visit of a randomised controlled trial. A questionnaire was administered, a pelvic examination carried out, and cervical samples obtained for detection of M genitalium, Neisseria gonorrhoeae, Chlamydia trachomatis, and Trichomonas vaginalis. Clinical signs potentially indicating cervicitis were cervical discharge, pus on the cervical swab, bleeding after sampling, and inflammatory cervix.

Results: Among 826 FSW, 26.3\% were infected with M genitalium. N gonorrhoeae was strongly and independently associated with each of the four signs of cervicitis (adjusted odds ratios (AOR): 4.1 to 6.0). The AOR for $C$ trachomatis were intermediate (1.3-4.1) and the AOR for $M$ genitalium were lower (between 1.6 and 1.8 ) but statistically significant $(p \leqslant 0.05)$ for each sign.

Conclusions: M genitalium is weakly associated with signs of cervicitis in west African FSW but is highly prevalent.
$\mathrm{D}$ uring the past decade, Mycoplasma genitalium has been identified as a relatively common cause of nongonococcal urethritis, both in industrialised countries and in the developing world. ${ }^{1-4}$ Ongoing investigations to define its pathogenicity in women have yielded somewhat contradictory findings. M genitalium was found more frequently in Japanese, American, and Swedish women with cervicitis than among controls, but no such association was found in France. ${ }^{5-8}$ In Kenyan women, $M$ genitalium infection was associated with acute endometritis ${ }^{9}$ but its prevalence was low among women with salpingitis. ${ }^{10} M$ genitalium was recovered more frequently in samples from British women with pelvic inflammatory disease than in controls. ${ }^{11}$ In Guinea-Bissau, $M$ genitalium infection was not associated with adverse outcomes of pregnancy. ${ }^{12}$ To identify the contribution of $M$ genitalium to the aetiology of cervicitis among female sex workers (FSW) in sub-Saharan Africa and its relative importance in the overall burden of sexually transmitted infections (STI), we looked for $M$ genitalium in cervical samples of women during cross sectional studies of FSW in Ghana and Bénin.

\section{METHODS}

FSW were recruited at FSW/STI clinics in Accra (Ghana), Cotonou and Porto Novo (Bénin) between March 2001 and April 2002, during the initial visit of a longitudinal study whose primary goal was to evaluate the effectiveness of monthly antibiotics on the prevalence of gonococcal and chlamydial infections, the results of which will be reported elsewhere..$^{13}$ The population of FSW thus represented a cross sectional sample, and most did not complain of symptoms of genital infection. The study protocol was approved by the national ethical committees of Bénin and Ghana. After informed consent was obtained, a questionnaire gathering demographic and behavioural information was administered. A pelvic examination was immediately carried out by a medical doctor or midwife; the cervix was visualised with a speculum. Clinical signs potentially indicating cervicitis were cervical discharge, pus on the cervical swab ("swab test"), bleeding after cervical sampling, inflammatory cervix (oedema and erythema). The presence of cervical motion tenderness was also recorded. A cervical swab was taken with the Amplicor collection kit according to recommended procedures, kept at $4-8^{\circ} \mathrm{C}$, and sent to a central laboratory in Canada. During this initial visit, antibiotics were given when clinically indicated.

The presence of Neisseria gonorrhoeae and Chlamydia trachomatis was documented using a commercial polymerase chain reaction (PCR) assay (Amplicor, Roche Diagnostics, Branchburg, NJ, USA). All repeatedly $N$ gonorrhoeae positive samples were retested using an in-house $16 \mathrm{~S}$ rRNA PCR assay ${ }^{14}$; samples were considered positive when confirmed by the 16S rRNA PCR assay. In-house PCR were used for detection of $M$ genitalium and Trichomonas vaginalis, as described elsewhere. ${ }^{3}$ The laboratory personnel performing these assays was blinded to the previously recorded clinical findings.

Data were entered and verified using Epi-Info 6.04, and analysis was performed with Stata 6.0. Proportions were compared with the $\chi^{2}$ test using Yates's correction or, when an expected cell value was less than 5, with Fisher's exact test. Logistic regression was used for multivariate analysis.

\section{RESULTS}

A total of 382 different FSW were recruited in Ghana and 444 in Bénin. In Ghana, they were all home based; in Bénin, 192 were brothel based, 223 were home based, and 29 usually picked up clients on the street. The prevalence of $M$ genitalium (MG) infection was $26.3 \%$ (217/826), compared to $16.0 \%$ (132/826) for $N$ gonorrhoeae (NG), 3.4\% (28/826) for $C$ trachomatis (CT) and $23.1 \%(191 / 826)$ for $T$ vaginalis (TV). Table 1 shows the frequency of co-infections among these women. The majority of women in whose cervical sample MG was found did not harbour any other co-pathogen.

Abbreviations: AOR, adjusted odds ratio; CT, Chlamydia trachomatis; FSW, female sex workers; MG, Mycoplasma genitalium; NAAT, nucleic acid amplification tests; NG, Neisseria gonorrhoeae; PCR, polymerase chain reaction; STI, sexually transmitted infections; TV, Trichomonas vaginalis 
Table 1 Frequency of co-infections between various pathogens, among 826 sex workers

\begin{tabular}{lllll}
\hline & N gonorrhoeae & C trachomatis & M genitalium & T vaginalis \\
\hline N gonorrhoeae $(n=132)$ & $57(43 \%)$ & $9(7 \%)$ & $42(32 \%)$ & $46(35 \%)$ \\
C trachomatis $(n=28)$ & $9(32 \%)$ & $8(29 \%)$ & $7(25 \%)$ & $12(43 \%)$ \\
M genitalium $(n=217)$ & $42(19 \%)$ & $7(3 \%)$ & $128(59 \%)$ & $62(29 \%)$ \\
$T$ vaginalis $(n=191)$ & $46(24 \%)$ & $12(6 \%)$ & $62(32 \%)$ & $96(50 \%)$ \\
\hline
\end{tabular}

Numbers in bold indicate the number and proportion of women infected with a single pathogen.

The total in each row exceeds $100 \%$ because some women were infected with more than two pathogens.

Table 2 displays the association between sexually transmitted pathogens, sociodemographic, and behavioural characteristics among the FSW, in univariate analyses. All four pathogens were more prevalent in FSW in Bénin than in Ghana (within Bénin, they were more prevalent in Porto Novo than in Cotonou, except for TV), but this was significantly so only for NG. While the prevalence of CT decreased with age, this was not seen for the other pathogens. MG and TV were significantly less prevalent in women with post-primary education than in their less educated counterparts, and more prevalent in women who were divorced or widowed. NG was less common in FSW who charged more than the average price for each intercourse. The presence of MG was not associated with the average number of clients per week, but was more common among FSW who had five or more clients the previous day, and in women who did not use a condom with all of their clients of the preceding week. NG and TV infections were also more common in women who did not use a condom with all clients of the preceding week. MG or NG infections were two times more frequent among HIV infected FSW than among their seronegative colleagues. Having had sex with a "boyfriend" in the previous week was not associated with a higher prevalence of MG, NG, CT, or TV (data not shown). In a logistic regression model, the independent correlates for infection with MG were HIV infection (adjusted odds ratio (AOR) 2.9; 95\% confidence interval (CI) 2.0 to 4.3 ; $p<0.001$ ), having only primary school (AOR: $2.4,95 \% \mathrm{CI}: 1.2$ to 4.7 ) or no formal education at all (AOR 2.5; 95\% CI 1.2 to 4.9; $\mathrm{p}=0.01$ ), experience of sex work shorter than 1 year (AOR $1.8 ; 95 \%$ CI 1.2 to $2.8 ; \mathrm{p}=0.005)$ and working in Porto Novo (AOR 1.7; 95\% CI 1.0 to 2.7; $\mathrm{p}=0.04$ ) or Cotonou (AOR 1.6; $95 \%$ CI 1.1 to $2.4 ; \mathrm{p}=0.01$ ) rather than in Accra.

Table 3 compares the frequency of clinical signs among women with or without various pathogens. The presence of vaginal discharge was significantly but weakly associated

Table 2 Risk factors for infection with Mycoplasma genitalium (MG), Neisseria gonorrhoeae (NG), Chlamydia trachomatis (CT), or Trichomonas vaginalis (TV) among sex workers in Ghana and Bénin

\begin{tabular}{|c|c|c|c|c|c|c|c|c|}
\hline & MG+/total & $\mathrm{p}$ Value & NG+/total & $p$ Value & $\mathrm{CT}+/$ total & $p$ Value & $\mathrm{TV}+/$ total & p Value \\
\hline \multicolumn{9}{|l|}{ City of work } \\
\hline Cotonou & $84 / 304(27.6 \%)$ & \multirow[t]{3}{*}{0.14} & $51 / 304(16.8 \%)$ & \multirow[t]{3}{*}{0.001} & $11 / 304(3.6 \%)$ & \multirow[t]{3}{*}{0.17} & 78/304 (25.7\%) & \multirow[t]{3}{*}{0.23} \\
\hline Porto Novo & $44 / 140(31.4 \%)$ & & $36 / 140(25.7 \%)$ & & $8 / 140(5.7 \%)$ & & $35 / 140(25.0 \%)$ & \\
\hline Accra & $89 / 382(23.3 \%)$ & & $45 / 382(11.8 \%)$ & & $9 / 382(2.4 \%)$ & & $78 / 382(20.4 \%)$ & \\
\hline \multicolumn{9}{|l|}{ Age (years) } \\
\hline $18-30$ & $67 / 263(25.5 \%)$ & \multirow[t]{3}{*}{0.09} & $44 / 263(16.7 \%)$ & \multirow[t]{3}{*}{0.90} & $15 / 263(5.7 \%)$ & \multirow[t]{3}{*}{0.04} & $61 / 263(23.2 \%)$ & \multirow[t]{3}{*}{0.31} \\
\hline $31-40$ & $108 / 365(29.6 \%)$ & & $58 / 365(15.9 \%)$ & & $9 / 365(2.5 \%)$ & & $77 / 365(21.1 \%)$ & \\
\hline More than 40 & $42 / 198(21.2 \%)$ & & $30 / 198(15.2 \%)$ & & $4 / 198$ (2.0\%) & & $53 / 198(26.8 \%)$ & \\
\hline \multicolumn{9}{|l|}{ Schooling } \\
\hline None & $72 / 244(29.5 \%)$ & \multirow[t]{3}{*}{0.03} & $46 / 244$ (18.9\%) & \multirow[t]{3}{*}{0.29} & $6 / 244(2.5 \%)$ & \multirow[t]{3}{*}{0.41} & $76 / 244(31.1 \%)$ & \multirow[t]{3}{*}{0.001} \\
\hline Primary & $130 / 488(26.6 \%)$ & & $70 / 488(14.3 \%)$ & & $20 / 488(4.1 \%)$ & & $98 / 488(20.1 \%)$ & \\
\hline Secondary or more & $14 / 91$ (15.4\%) & & $15 / 91$ (16.5\%) & & $2 / 91(2.2 \%)$ & & $17 / 91$ (18.7\%) & \\
\hline \multicolumn{9}{|l|}{ Marital status } \\
\hline Never married & $59 / 273(21.6 \%)$ & \multirow[t]{3}{*}{0.04} & $31 / 273$ (11.4\%) & \multirow[t]{3}{*}{0.04} & $15 / 273(5.5 \%)$ & \multirow[t]{3}{*}{0.048} & 50/273 (18.3\%) & \multirow[t]{3}{*}{0.01} \\
\hline Currently married & $22 / 95(23.2 \%)$ & & $17 / 95(17.9 \%)$ & & $1 / 95(1.1 \%)$ & & $17 / 95(17.9 \%)$ & \\
\hline \multirow{2}{*}{\multicolumn{9}{|c|}{ Price per intercourse* }} \\
\hline & & & & & & & & \\
\hline$\leqslant 500$ CFA $/ 5000 \mathrm{Ce}$ & $179 / 656(27.3 \%)$ & \multirow[t]{2}{*}{0.31} & $119 / 656(18.1 \%)$ & \multirow[t]{2}{*}{0.001} & $21 / 656(3.2 \%)$ & \multirow[t]{2}{*}{0.55} & $158 / 656(24.1 \%)$ & \multirow[t]{2}{*}{0.09} \\
\hline$>500 \mathrm{CFA} / 5000 \mathrm{Ce}$ & $35 / 153(22.9 \%)$ & & $11 / 153(7.2 \%)$ & & $7 / 153(4.6 \%)$ & & $27 / 153(17.6 \%)$ & \\
\hline Duration of sex work & & & & & & & & \\
\hline Less than 1 year & $91 / 295$ (30.8\%) & 0.07 & 48/295 (16.3\%) & 0.94 & $15 / 295(5.1 \%)$ & 0.20 & $67 / 295(22.7 \%)$ & 0.47 \\
\hline $1-3$ years & $66 / 285(23.2 \%)$ & & $45 / 285(15.8 \%)$ & & $5 / 285(1.8 \%)$ & & $62 / 285(21.8 \%)$ & \\
\hline More than 3 years & $59 / 243(24.3 \%)$ & & $39 / 243(16.0 \%)$ & & $8 / 243(3.3 \%)$ & & $62 / 243(25.5 \%)$ & \\
\hline Average number of client & & & & & & & & \\
\hline per week & & & & & & & & \\
\hline 14 or less & $55 / 232(23.7 \%)$ & 0.50 & $28 / 232(12.1 \%)$ & 0.13 & $8 / 232(3.4 \%)$ & 0.99 & $56 / 232(24.1 \%)$ & 0.92 \\
\hline $15-28$ & $85 / 320(26.6 \%)$ & & $59 / 320(18.4 \%)$ & & $11 / 320(3.4 \%)$ & & $73 / 320(22.8 \%)$ & \\
\hline more than 28 & $70 / 246(28.5 \%)$ & & $39 / 246(15.9 \%)$ & & $8 / 246(3.3 \%)$ & & $56 / 246(22.8 \%)$ & \\
\hline $\begin{array}{l}\text { Number of clients last } \\
\text { working day }\end{array}$ & & & & & & & & \\
\hline $0-2$ & $55 / 222(24.8 \%)$ & 0.04 & $30 / 222(13.5 \%)$ & 0.14 & $6 / 222(2.7 \%)$ & 0.73 & $49 / 222(22.1 \%)$ & 0.84 \\
\hline $3-4$ & $76 / 329(23.1 \%)$ & & $48 / 329(14.6 \%)$ & & $13 / 329(4.0 \%)$ & & $79 / 329(24.0 \%)$ & \\
\hline 5 or more & $84 / 261$ (32.2\%) & & $51 / 261(19.5 \%)$ & & $9 / 261$ (3.4\%) & & $63 / 261(24.1 \%)$ & \\
\hline Condom use, last week & & & & & & & & \\
\hline Not with all clients & 62/188 (33.0\%) & 0.02 & $49 / 188(26.1 \%)$ & $<0.001$ & $8 / 188(4.3 \%)$ & 0.65 & $60 / 188(31.9 \%)$ & 0.003 \\
\hline With all clients & $144 / 592(24.3 \%)$ & & $77 / 592(13.0 \%)$ & & $19 / 592(3.2 \%)$ & & $124 / 592(20.9 \%)$ & \\
\hline HIV & & & & & & & & \\
\hline Negative & $51 / 308(16.6 \%)$ & $<0.001$ & $30 / 308$ (9.7\%) & $<0.001$ & $14 / 308(4.5 \%)$ & 0.13 & 68/308 (22.1\%) & 0.62 \\
\hline $\begin{array}{l}\text { Positive (HIV-1 } \\
\text { and/or HIV-2) }\end{array}$ & $156 / 473(33.0 \%)$ & & $95 / 473(20.1 \%)$ & & $11 / 473(2.3 \%)$ & & $113 / 473(23.9 \%)$ & \\
\hline
\end{tabular}




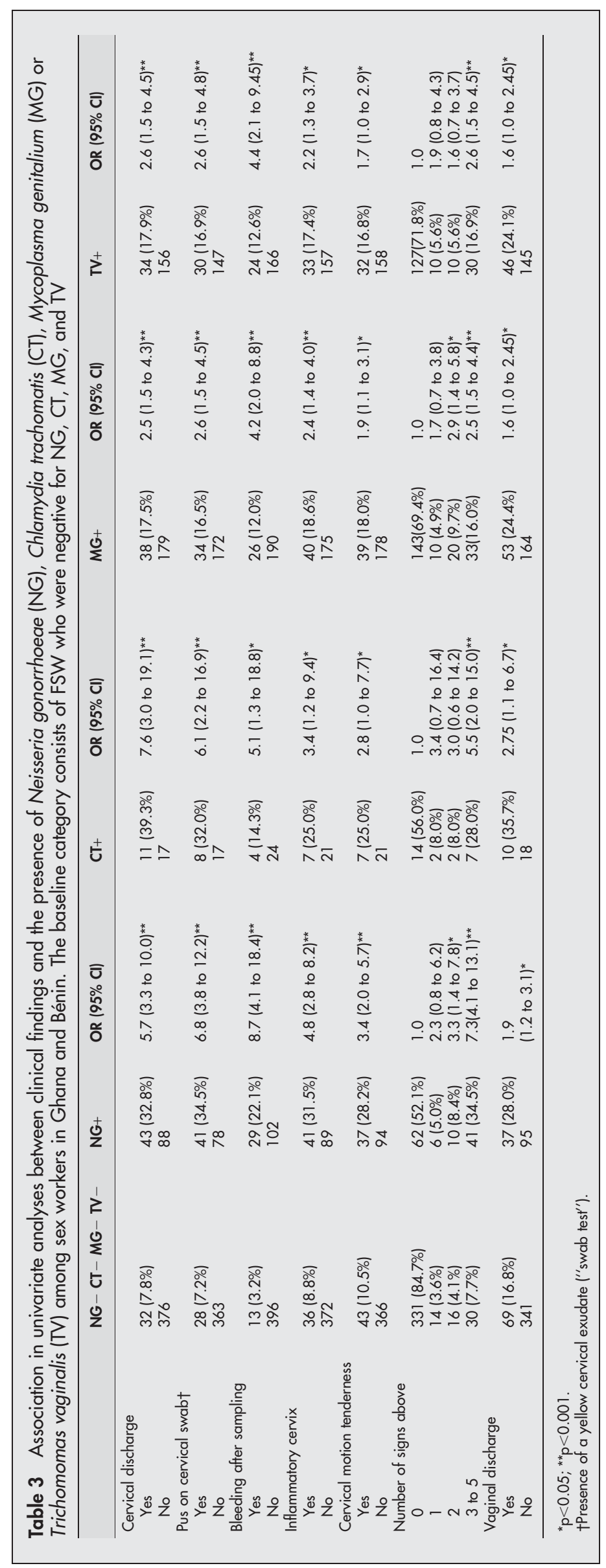


Table 4 Association between Mycoplasma genitalium and clinical findings, according to whether vaginal discharge had been noted. The baseline category consists of FSW who were negative for NG, CT, MG, and TV

\begin{tabular}{|c|c|c|c|c|c|c|c|}
\hline & \multicolumn{3}{|l|}{ No vaginal discharge } & \multicolumn{3}{|c|}{ Vaginal discharge present } & \multirow{2}{*}{$\begin{array}{l}\text { p Value, test } \\
\text { for interaction }\end{array}$} \\
\hline & $\mathrm{NG}-\mathrm{CT}-\mathrm{MG}-\mathrm{TV}-$ & MG+ & OR $(95 \% \mathrm{Cl})$ & NG- CT- MG- TV- & MG+ & OR $(95 \% \mathrm{Cl})$ & \\
\hline \multicolumn{8}{|c|}{ Cervical discharge } \\
\hline Yes & $24(7.1 \%)$ & $33(20.1 \%)$ & 3.3 & $8(11.8 \%)$ & $5(9.4 \%)$ & & 0.03 \\
\hline No & 316 & 131 & $(1.8 \text { to } 6.1)^{* *}$ & & & $(0.2$ to 2.9$)$ & \\
\hline \multicolumn{8}{|c|}{ Pus on cervical swabt } \\
\hline Yes & $20(6.0 \%)$ & $29(18.0 \%)$ & 3.5 & $8(14.5 \%)$ & $5(11.1 \%)$ & 0.7 & \\
\hline No & 316 & 132 & $(1.8 \text { to } 6.7)^{\star *}$ & 47 & 40 & $(0.2$ to 2.8$)$ & 0.02 \\
\hline \multicolumn{8}{|c|}{ Bleeding after sampling } \\
\hline Yes & $8(2.4 \%)$ & $18(11.0 \%)$ & 5.2 & $5(7.2 \%)$ & $8(15.1 \%)$ & 2.3 & 0.27 \\
\hline No & 332 & 145 & $(2.0 \text { to } 13.4)^{* *}$ & 64 & & $(0.6$ to 8.8$)$ & \\
\hline $\begin{array}{l}\text { Intlamm } \\
\text { Yes }\end{array}$ & $23(6.8 \%)$ & $31(19.0 \%)$ & 3.2 & $13(19.1 \%)$ & $9(17.3 \%)$ & & 0.02 \\
\hline No & 317 & 132 & $(1.7 \text { to } 6.0)^{* *}$ & 55 & 43 & $(0.3$ to 2.5$)$ & \\
\hline \multicolumn{8}{|c|}{ Cervical motion } \\
\hline tendern & & & & & & & \\
\hline Yes & $27(7.9 \%)$ & $27(16.5 \%)$ & 2.3 & $16(23.2 \%)$ & $12(22.6 \%)$ & 1.0 & 0.10 \\
\hline No & 313 & 137 & $(1.2 \text { to } 4.2)^{*}$ & 53 & & (0.4 to 2.5$)$ & \\
\hline
\end{tabular}

with each of these four pathogens. Vulvar inflammation was uncommon and not associated significantly with any pathogen (data not shown). Each of the four signs potentially indicating cervicitis (cervical discharge, pus on the cervical swab, bleeding after sampling, inflammatory cervix) as well as cervical motion tenderness were associated with each of the four pathogens. By and large, the unadjusted odds ratios for signs of cervicitis were higher for NG and CT, and lower for MG and TV. The presence of a genital ulcer on clinical examination was not associated with a positive PCR for MG, NG, CT, or TV (data not shown). However, as shown in table 4, the associations between signs of cervicitis or cervical motion tenderness and the presence of MG were stronger among women in whom no vaginal discharge was present; for three signs, there was a significant interaction.

Logistic regression analyses were carried out for each of the four signs of cervicitis and for cervical motion tenderness as the outcomes, in which the odds ratios for each pathogen were adjusted for the presence of the other three pathogens and, in three of the models, for age (in models for cervical discharge and pus on swab, age did not improve the fit and was not kept). The presence of vaginal discharge did not improve the fit of any of the models and was thus not further considered. When adjusted for the presence of NG, CT, and MG, the presence of TV was no longer significantly associated with any of the five clinical signs and was also removed from the final models. As shown in table 5, NG was strongly and independently associated with each of the four signs of cervicitis as well as with cervical motion tenderness. The adjusted odds ratios for CT were lower than those of NG, and either similar or somewhat higher than those of MG. However, owing to its higher prevalence, the associations between MG and signs of cervicitis were all statistically significant; there was no significant association with cervical motion tenderness.

Table 6 shows the sensitivity, specificity, positive predictive value, and negative predictive values of two clinical scores to identify among FSW the presence of agents of cervicitis, without any laboratory back-up. The score with the highest $\mathrm{PPV} /$ prevalence ratio was the one incorporating the five signs and defining as positive any woman in whom at least two of these signs were found. This score had a sensitivity of $43 \%$ and a positive predictive value of $36 \%$ in identifying FSW with gonococcal infection. When taking into consideration all three pathogens, the positive predictive value jumped to $61 \%$ but the sensitivity dropped to $29 \%$.

\section{DISCUSSION}

Among 826 FSW seen during a cross sectional survey, associations were found between $M$ genitalium and the presence of four signs generally thought to be indicative of cervicitis. As this was a post hoc initiative exploiting data accumulated during the course of another study, ${ }^{13}$ we did not obtain Gram stains of cervical secretions which might have given us a more objective definition of cervicitis. ${ }^{6}$ However, this point is debatable as the cut off for the presence of mucopurulent cervicitis used by other researchers varies from $\geqslant 10, \geqslant 20$, and $\geqslant 30$ polymorphonuclear leucocytes per oil immersion field, ${ }^{15}$ underlining that there is no clear cut cytological definition of cervicitis.

Is the association between $M$ genitalium and signs of cervicitis causal? Some of the Bradford Hill ${ }^{16}$ criteria have been met by studies addressing this issue, including ours:

Table 5 Associations in multivariate analysis between clinical findings of cervicitis and the presence of $\mathrm{N}$ gonorrhoeae, C trachomatis, and M genitalium among sex workers in Ghana and Bénin*

\begin{tabular}{|c|c|c|c|c|c|c|}
\hline & \multicolumn{2}{|l|}{ N gonorrhoeae } & \multicolumn{2}{|l|}{ C trachomatis } & \multicolumn{2}{|l|}{ M genitalium } \\
\hline & AOR $(95 \% \mathrm{Cl})$ & p Value & AOR $(95 \% \mathrm{Cl})$ & p Value & AOR $(95 \% \mathrm{Cl})$ & p Value \\
\hline Cervical discharge & $4.4(2.8$ to 7.0$)$ & $<0.001$ & 4.1 (1.8 to 9.3$)$ & 0.002 & $1.6(1.0$ to 2.5$)$ & 0.05 \\
\hline Pus on swab & $6.0(3.7$ to 9.6$)$ & $<0.001$ & $3.3(1.3$ to 8.4$)$ & 0.02 & $1.6(1.0$ to 2.7$)$ & 0.047 \\
\hline Bleeding after sampling & $5.0(2.9$ to 8.6$)$ & $<0.001$ & $1.3(0.4$ to 4.1$)$ & 0.69 & $1.8(1.0$ to 3.1$)$ & 0.04 \\
\hline Inflammatory cervix & 4.1 (2.6 to 6.4$)$ & $<0.001$ & $1.5(0.6$ to 3.8$)$ & 0.42 & $1.6(1.0$ to 2.5$)$ & 0.04 \\
\hline Cervical motion tenderness & 3.0 (1.9 to 4.7$)$ & $<0.001$ & $1.4(0.5$ to 3.5$)$ & 0.50 & $1.3(0.9$ to 2.0$)$ & 0.19 \\
\hline
\end{tabular}

$\mathrm{AOR}$, adjusted odds ratio; $\mathrm{Cl}$, confidence interval.

*The adjusted odds ratios were obtained after controlling for the presence of the other pathogens, and for age in the models with post-sampling bleeding, inflammatory cervix, cervical motion tenderness. For cervical discharge and pus on swab, age did not enhance the fit of the model and was not kept. 
Table 6 Performance of diagnosis of cervical infections based on scores derived from combinations of clinical findings among sex workers

\begin{tabular}{|c|c|c|c|c|}
\hline & $N$ gonorrhoeae & C trachomatis & M genitalium & NG, CT, MG \\
\hline \multicolumn{5}{|c|}{$\begin{array}{l}\text { Score defined as positive if two or more of the following signs are present: cervical discharge, pus on swab, bleeding after sampling, inflammatory cervix, cervica } \\
\text { motion tenderness on examination }\end{array}$} \\
\hline Sensitivity & $51 / 119(43 \%)$ & $9 / 25(36 \%)$ & $53 / 206(26 \%)$ & $86 / 298(29 \%)$ \\
\hline Specificity & $567 / 657(86 \%)$ & $619 / 751(82 \%)$ & $482 / 570(85 \%)$ & $423 / 478(88 \%)$ \\
\hline PPV & $51 / 141(36 \%)$ & $9 / 141(6 \%)$ & $53 / 141(38 \%)$ & $86 / 141(61 \%)$ \\
\hline $\mathrm{PPV} /$ prevalence & 2.26 & 1.88 & 1.43 & 1.58 \\
\hline NPV & $567 / 635(89 \%)$ & $619 / 635$ (97\%) & $482 / 635$ (76\%) & $423 / 635(67 \%)$ \\
\hline \multicolumn{5}{|c|}{$\begin{array}{l}\text { Score defined as positive if one or more of the following signs are present: pus on swab, bleeding after sampling, inflammatory cervix, cervical motion tenderness } \\
\text { on examination }\end{array}$} \\
\hline Sensitivity & $57 / 119(48 \%)$ & $10 / 25(40 \%)$ & $61 / 206(30 \%)$ & $97 / 298(33 \%)$ \\
\hline Specificity & $545 / 657(83 \%)$ & $592 / 751(79 \%)$ & $462 / 570(81 \%)$ & $406 / 478(85 \%)$ \\
\hline PPV & $57 / 169(34 \%)$ & $10 / 169(6 \%)$ & $61 / 169(36 \%)$ & $97 / 169(57 \%)$ \\
\hline $\mathrm{PPV} /$ prevalence & 2.11 & 1.74 & 1.37 & 1.48 \\
\hline NPV & $545 / 607(90 \%)$ & $592 / 607(98 \%)$ & $462 / 607(76 \%)$ & $406 / 607(67 \%)$ \\
\hline
\end{tabular}

consistency (an association between $M$ genitalium and cervicitis has been found in Japan, the United States, Sweden, and now west Africa $^{5-7}$ ), biological plausibility (experimental infections in primates ${ }^{17}$ ), analogy ( $M$ genitalium is clearly associated with urethritis in men, ${ }^{1-4}$ agents of urethritis such as $N$ gonorrhoeae and $C$ trachomatis cause cervicitis in women, thus it would make sense for $M$ genitalium to cause cervicitis as well), and coherence (many women with cervicitis have no known pathogen found ${ }^{15}$ ). Temporality and dose response have not been addressed by the literature so far, and the strength of the associations (that is, the odds ratio) is rather weak. The only study that did not find an association between $M$ genitalium and cervicitis included only women with a vaginal discharge ${ }^{8}$ : our findings suggest that, perhaps as a consequence of its modest pathogenicity, the signs of $M$ genitalium induced cervicitis are difficult to elicit in women who also have vaginitis. Ultimately, experimental data will provide the definitive answer: does the treatment of women with cervicitis, among whom $M$ genitalium but not $N$ gonorrhoeae nor $C$ trachomatis has been recovered, with a drug active against $M$ genitalium lead to the disappearance of cervicitis in a timely manner?

In this population of west African FSW, among whom there was a high frequency of condom use during transactional sex, $M$ genitalium was eight times more prevalent than $C$ trachomatis and 1.6 times more prevalent than $N$ gonorrhoeae. It might be that the natural history of $M$ genitalium cervical infection is characterised by a longer duration of infection, and this could be further compounded by the frequent coinfection with HIV. Alternatively, as $M$ genitalium is less strongly associated with signs of cervicitis than are the gonococcus and $C$ trachomatis, $M$ genitalium infected sex workers might seek care and receive antibiotics less often than when they are infected with the other two pathogens.

$C$ trachomatis was remarkably uncommon (3.4\%) among this population of FSW, even among those aged 30 years or less (5.7\%). Low prevalence of $C$ trachomatis among west African FSW has been noted in recent surveys in Cotonou $(5.1 \%),{ }^{18}$ in a multicentre study which included sites in Côte d'Ivoire and Bénin (1.9\% in Abidjan and $5.9 \%$ in Cotonou) ${ }^{19}$ (B Mâsse, personal communication), and in the four cities study which documented a prevalence of $4 \%$ among FSW in Cotonou, compared to $8 \%$ in Kisumu (Kenya), 9\% in Ndola (Zambia), and $18 \%$ in Yaoundé (Cameroon) ${ }^{20}$ (all of which used nucleic acid amplification tests (NAAT)). This was mirrored at the population level, with a prevalence of $C$ trachomatis as low as $1.3 \%$ among a random sample of adult women in Cotonou, compared to $4.5 \%$ in Kisumu, $2.9 \%$ in Ndola, and $9.4 \%$ in Yaoundé, ${ }^{21}$ perhaps reflecting to some extent the long standing presence in Bénin, Ghana, and Côte d'Ivoire of interventions targeting FSW, with relatively high rates of condom use and reasonable access to specialised clinics where treatment against $C$ trachomatis and $N$ gonorrhoeae is provided when cervicitis is suspected. The prevalence of gonorrhoea was not appreciably lower in sex workers of Cotonou than in the other three cities ${ }^{20}$ : $C$ trachomatis being less transmissible than $N$ gonorrhoeae, ${ }^{22}$ its prevalence might be more readily lowered by a high rate of condom use during transactional sex. Recent studies of FSW from east Africa, also using NAAT, have documented somewhat higher $C$ trachomatis prevalences: $7 \%$ in Kenya, $12 \%$ in Tanzania, $13 \%$ in South Africa, and $16-17 \%$ in Madagascar. ${ }^{23-26}$ Whether populations vary in their intrinsic, biological susceptibility to sexually transmitted pathogens or simply differ in the frequency of condom use during transactional sex deserves further study.

The population attributable fraction of a given pathogen with regard to a given syndrome depends on both the prevalence of the pathogen, and the strength (odds ratio) of the association. In this case, taking as the measure of association the means of the adjusted odds ratios of the four signs of cervicitis shown in table 5 (4.9 for $N$ gonorrhoeae, 2.6 for $C$ trachomatis, 1.7 for $M$ genitalium) and the prevalences that we measured, it is possible to estimate that $38 \%$ of cases of clinical cervicitis are caused by $N$ gonorrhoeae, $16 \%$ by $M$ genitalium, and $5 \%$ by $C$ trachomatis. The gonococcus thus remains the predominant agent of cervicitis in this population of FSW, but $M$ genitalium contributes more than $C$ trachomatis.

Several independent correlates of $M$ genitalium infection among FSW were identified. It was more frequent in women with little or no formal education, which might be related to health seeking behaviour or condom use. $M$ genitalium was also more common in FSW who had been involved for less than 1 year in the trade, which might relate to the same factors, or to a lack of acquired immunity to the pathogen. Work in Porto Novo or Cotonou rather than in Accra was a risk factor, which we believe is related to a lower rate of condom use in Bénin as documented in surveys of clients. ${ }^{27-29}$ In the current study, adjustment for condom use (as a marker of the number of unprotected intercourses) reported by the FSW did not enhance the fit of the model and was thus not kept in the final model, emphasising that self reports by FSW might be unreliable, leading to the presence of residual confounding. In this context, the rather strong independent association between $M$ genitalium and HIV infections, also described in other studies ${ }^{12}{ }^{30}$ should be interpreted cautiously. HIV infection was also associated with the presence of gonococcal cervicitis, which could be interpreted as an additional argument suggesting that there was some residual confounding. Other potential mechanisms, which could not be sorted out because of the cross sectional design, are either that $M$ genitalium might facilitate 
the transmission of HIV from clients to FSW, that HIV might prolong the duration of untreated $M$ genitalium infection, and that HIV might reduce the effectiveness of antibiotics, given for other reasons, against $M$ genitalium. Only longitudinal studies could answer these questions.

Where does that lead us with regard to the syndromic management of STI among FSW in developing countries with no access to laboratory back up? For FSW, the administration of a treatment against agents of cervicitis seems warranted when they are found to have two or more of the following signs: cervical discharge, pus on swab, bleeding after sampling, inflammatory cervix, cervical motion tenderness. One could also drop cervical discharge, and consider as having cervicitis any FSW with at least one of the four other signs. Either strategy would lead to the proper treatment of almost half of the cases of gonococcal infections and, if one considers the presence of $N$ gonorrhoeae, $C$ trachomatis, and $M$ genitalium, in the overtreatment of $39-43 \%$ of women found to fulfil these criteria. The higher prevalence of sexually transmitted pathogens among sex workers result in a positive predictive value much higher than among women not involved in transactional sex, and these recommendations cannot be extrapolated to other populations. Furthermore, the identification of signs of cervicitis by polyvalent health care providers who carry out speculum examinations infrequently might be less reliable. ${ }^{31}$ This argues in favour of organising the care of FSW around specialised nurses or medical officers, working within primary healthcare institutions. The proper control of these infections among the core groups of FSW might be the key to reducing their prevalence in the general adult population. ${ }^{32}$

\section{ACKNOWLEDGEMENTS}

We are indebted to all study participants and health workers involved in data collection. The Canadian International Development Agency (CIDA) funds the West Africa Project to Combat AIDS and STI, the public health intervention around which this study was organised. CIDA had no role in study design, data collection, analysis, interpretation or in the writing up of this article. Annie-Claude Labbé was recipient of a Canadian Institutes of Health Research postdoctoral fellowship and of a Benjamin H Kean Traveling Fellowship in Tropical Medicine (from the American Society of Tropical Medicine and Hygiene). Michel Alary is a senior research scholar of the Fonds de Recherche en Santé du Québec.

\section{CONTRIBUTORS}

JP conceived the study; ACL, KN, AD, CAA, and HM supervised the field work at both sites; ACL, SD and EF carried out laboratory analyses; JP, ACL, and MA performed the statistical analyses; JP wrote the first draft of the manuscript and all authors were involved in writing the subsequent versions of the manuscript.

\footnotetext{
Authors' affiliations

J Pépin, S Deslandes, E Frost, Department of Microbiology and Infectious Diseases, University of Sherbrooke, Sherbrooke, Canada A-C Labbé, Hôpital Maisonneuve-Rosemont, Montréal, Canada K Nzambi, C Asamoah-Adu, West Africa Project to Combat AIDS and STI, Accra, Ghana

M Alary, Centre Hospitalier Affilié Universitaire and Laval University, Québec, Canada

A Dzokoto, Ghana Health Service, Accra, Ghana

H Méda, West Africa Project to Combat AIDS and STI, Cotonou, Bénin

Conflicts of interest: none.

\section{REFERENCES}

1 Taylor-Robinson D, Horner PJ. The role of Mycoplasma genitalium in nongonococcal urethritis. Sex Transm Infect $2001 ; 77: 229-31$.

2 Horner $\mathbf{P}$, Thomas B, Gilroy CB, et al. Role of Mycoplasma genitalium and Ureaplasma urealyticum in acute and chronic nongonococcal urethritis. Clin Infect Dis 2001;32:995-1003.
}

3 Pépin J, Sobela F, Deslandes S, et al. Etiology of urethral discharge in West Africa: the role of Mycoplasma genitalium and Trichomonas vaginalis. Bull World Health Organ 2001;79:118-26.

4 Morency P, Dubois MJ, Grésenguet G, et al. Aetiology of urethral discharge in Bangui, Central African Republic. Sex Transm Infect 2001;77:125-9.

5 Uno M, Deguchi T, Komeda H, et al. Mycoplasma genitalium in the cervices of Japanese women. Sex Transm Dis 1997;24:284-6.

6 Manhart LE, Critchlow CW, Holmes KK, et al. Mucopurulent cervicitis and Mycoplasma genitalium. J Infect Dis 2003;187:650-7.

7 Anagrius C, Loré B. Association of Mycoplasma genitalium with cervicitis and female urethritis. Ottawa: 15th Biennal Congress of the International Society for Sexually Transmitted Diseases Research, 2003. Abstract 0732.

8 Casin I, Vexiau-Robert D, De La Salmonière P, et al. High prevalence of Mycoplasma genitalium in the lower genitourinary tract of women attending a sexually transmitted disease clinic in Paris, France. Sex Transm Dis 2002;29:353-9.

9 Cohen C, Mugo NR, Astete SG, et al. Detection of Mycoplasma genitalium in lapararoscopically diagnosed acute salpingitis in Nairobi, Kenya. Ottawa: 15th Biennal Congress of the International Society for Sexually Transmitted Diseases Research, 2003. Abstract 0420.

10 Cohen CR, Manhart LE, Bukusi EA, et al. Association between Mycoplasma genitalium and acute endometritis. Lancet 2002;359:765-6.

11 Simms I, Eastick K, Mallinson H, et al. Associations between Mycoplasma genitalium, Chlamydia trachomatis, and pelvic inflammatory disease. Sex Transm Infect 2003;79:154-6.

12 Labbé AC, Frost E, Deslandes S, et al. Mycoplasma genitalium is not associated with adverse outcomes of pregnancy in Guinea-Bissau. Sex Transm Infect 2002;78:289-91.

13 Labbé AC, Dzokoto A, Khonde N, et al. A randomised placebo-controlled trial of routine monthly antibiotics against gonococcal and chlamydial infections among female sex workers in Ghana and Bénin: intention-to-treat analysis. Ottawa: 15th Biennal Congress of the International Society for Sexually Transmitted Diseases Research, 2003. Abstract 0524.

14 Diemert DJ, Libman MD, Lebel P. Confirmation by 16S rRNA PCR of the Cobas Amplicor CT/NG test for diagnosis of Neisseria gonorrhoeae infection in a low-prevalence population. J Clin Microbiol 2002;40:4056-9.

15 Holmes KK, Stamm WE. Lower genital tract infection syndromes in women. In: Holmes KK, Sparling PF, Mardh PA, et al, eds. Sexually transmitted diseases. New York: McGraw-Hill, 1999:761-81.

16 Bradford Hill A. The environment and disease: association or causation? Proc R Soc Med 1965;58:295-300.

17 Tully JG, Taylor-Robinson D, Rose DL, et al. Urogenital challenge of primate species with Mycoplasma genitalium and characteristics of infection induced in chimpanzees. J Infect Dis 1986;153:1046-54

18 Alary M, Mukenge-Tshibaka L, Bernier F, et al. Decline in the prevalence of HIV and sexually transmitted diseases among female sex workers in Cotonou, Bénin, 1993-1999. AIDS 2002;16:463-70.

19 Van Damme L, Ramjee G, Alary M, et al. Effectiveness of COL-1492, a nonoxynol-9 vaginal gel, on HIV-1 transmission in female sex workers: a randomised controlled trial. Lancet 2002;360:971-7.

20 Morison L, Weiss HA, Buvé A, et al. Commercial sex and the spread of HIV in four cities in sub-Saharan Africa. AIDS 2001;15(suppl 4):S61-9.

21 Buvé A, Weiss HA, Laga $M$, et al. The epidemiology of gonorrhoea, chlamydial infection and syphilis in four African cities. AIDS 2001;15(suppl 4):S79-S88.

22 Brunham RC, Plummer FA. A general model of sexually transmitted disease epidemiology and its implication for control. Med Clin N America 1990;74:39-1352.

23 Fonck K, Kaul R, Kimani J, et al. A randomized, placebo-controlled trial of monthly azithromycin prophylaxis to prevent sexually transmitted infections and HIV-1 in Kenyan sex workers : study design and baseline findings. Int J STD AIDS 2000;11:804-11.

24 Riedner G, Rusizoka M, Hoffmann $O$, et al. Baseline survey of sexually transmitted infections in a cohort of female bar workers in Mbeya Region, Tanzania. Sex Transm Infect 2003;79:382-7.

25 Williams BG, Taljaard D, Campbell CM, et al. Changing patterns of knowledge, reported behaviour and sexually transmitted infections in South African gold mining community. AIDS 2003;17:2099-107.

26 Behets FRMTF, Rasolofomanana FR, Van Damme K, et al. Evidence-based treatment guidelines for sexually transmitted infections developed with and for female sex workers. Trop Med Int Health 2003;8:251-8.

27 Côté AM, Sobela F, Dzokoto A, et al. Transactional sex is the driving force in the dynamics of HIV in Accra, Ghana. AIDS 2004;18:917-25.

28 Lowndes CM, Alary M, Gnintoungbé CAB, et al. Management of sexually transmitted diseases and HIV prevention in men at high risk: targeting clients and non-paying sexual partners of female sex workers in Bénin. AIDS 2000; 14:2523-34

29 Labbé AC, Gnintoungbe C, Meda H, et al. Clients of female sex workers in Cotonou, Bénin: risk factors and prevalence of sexually transmitted infections. Barcelona: XIV International AIDS Conference, 2002. Abstract ThPeC7582.

30 Perez G, Skurnick JH, Denny TN, et al. Herpes simplex type II and Mycoplasma genitalium as risk factors for heterosexual HIV transmission: report from the heterosexual HIV transmission study. Int J Infect Dis 1998:3:5-11.

31 Wi T, Mesola V, Manalastas R, et al. Syndromic approach to detection of gonococal and chlamydial infections among female sex workers in two Philippine cities. Sex Transm Inf 1998;74(Suppl 1): S1 18-22.

32 Pépin J, Deslandes S, Khonde N, et al. Low prevalence of cervical infections in women with vaginal discharge in west Africa: implications for syndromic management. Sex Transm Infect 2004;80:230-5. 